\title{
Tourism information system to facilitate tourists in determining travel routes in a web-based city of Pagar Alam
}

\author{
Fitria Rahmadayanti*, Evy Septriani \\ Program Studi Teknik Informatika Sekolah Tinggi Teknologi Pagar Alam \\ Email Korespondensi : "ria.ria.rr71@gmail.com
}

\begin{abstract}
This study aims to create a Web-based Tourism Information System. In conveying about tourism, promotion is still carried out through the mass media of television, newspapers, banners and baleho. The impact is that tourists still find it difficult to determine the planning of a tour in the city of Pagar Alam. The system development method used is the Web Engineering method with five stages of Customer Communication, Planning, Modeling, Construction and Deployment. Therefore, the researcher will create a web-based tourism information system in order to make it easier for tourists to find information such as tourist attraction data, hotel data and restaurant data as well as places that are connected to the google map. With the existence of a web-based information system can help spread promotions to tourists widely to increase tourist visits to the City of Pagar Alam.

Keyword: Information Systems, Tourism and Web Engineering
\end{abstract}

\section{Pendahuluan}

Di era globalisasi saat ini perkembangan teknologi informasi berkembang sangatlah pesat. Suatu informasi dengan mudahnya didapat yang dikemas melalui sistem atau aplikasi dan didukung oleh kemajuan internet. Sistem informasi merupakan gabungan dari empat bagian utama. Keempat bagian utama` tersebut mencakupperangkat lunak (software), perangkat keras (hardware), infrastruktur, dan sumber daya manusia (SDM) yang terlatih. Keempat bagian utama ini saling berkaitan untuk menciptakan sebuah sistem yang dapat mengolah data menjadi informasi yang bermanfaat [1]. Dengan adanya Sistem Informasi, pekerjaan dapat dilakukan dengan mudah oleh penggunanya seperti hal nya sistem informasi pariwisata yang dapat mempermudah para wisatawan untuk mengetahui banyak informasi mengenai objek wisata melalui sistem.

Kota Pagar Alam merupakan salah satu kota di Provinsi Sumatera Selatan yang terkenal dengan objek wisata yang menawan. Akan tetapi dalam penyampaian mengenai pariwisata masih menggunakan promosi melalui media masa televisi, surat kabar, radio, spanduk dan baleho. Teknik penyampaian seperti ini belum cukup untuk menginformasikan kepada seluruh wisatawan secara luas. Para wisatawan akan merasa kesulitan dalam menentukan perencanaan wisata karna belum tau persis mengenai objek wisata yang ada di kota Pagar Alam.

Oleh karena itu, peneliti membuat sebuah sistem informasi pariwisata berbasis web secara online yang dapat digunakan untuk memudahkan sekaligus membantu mempromosikan kepada para wisatawan mengenai objek wisata, disertai juga hotel dan restoran yang ada di kota Pagar Alam. Dengan program 
sistem informasi berbasis web ini dapat membantu meningkatkan penyebaran informasi mengenai objek wisata secara luas dan meningkatkan daya tarik wisatawan dalam berwisata di Kota Pagar Alam.

Apikasi pendukung dari sistem yang di bangun yaitu database, Database adalah sistem yang terkomputerisasi yang bertujuan untuk memelihara data yang sudah diolah atau informasi dan membuat informasi tersebut tersedia pada saat dibutuhkan [2]. MySQL adalah sebuah perangkat lunak sistem manajemen basis data sql atau DBMS yang multiihread, multi-user, dengan sekitar 6 (enam) juta instalasi diseluruh dunia [3]. Perl Hyper Text Preprocessor (PHP) adalah program interpreter yaitu proses penerjemahan baris kode sumber menjadi kode mesin yang dimengerti computer secara langsung pada saat baris kode dijalankan. PHP disebut sebagai pemrograman. Server Side Programing karena seluruh prosesnya dijalankan pada server [4]. Dreamweaver merupakan software utama yang di gunakan oleh desainer web dan programmer web untuk mengembangkan suatu situs web. Dreamweaver memiliki ruang kerja, fasilitas, dan kemampuan yang mampu meningkatkan produktivitas dan efektivitas, baik dalam desain maupun pembuatan situs web [5].

Penelitian ini membantu pemerintahan dalam mengenal Pariwisata yang ada di Kota Pagar Alam, dimana sistem ini akan memberikan informasi data objek wisata, data hotel dan data restoran serta tempat yang dihubungkan ke google map. Dari sistem yang dibuat akan menjadikan sebagai media promosi Kota Pagar Alam untuk menambah minat para wisatawan berkunjung ke Pagar Alam. Berdasarkan latar belakang tersebut, maka perlu dilakukan penelitian untuk membuat sistem informasi berbasis web, maka peneliti mengajukan judul "Sistem Informasi Pariwisata Untuk Memudahkan Wisatawan Dalam Menentukan Rute Perjalanan Berwisata di Kota Pagar Alam Berbasis Web".

\section{Metode}

\subsection{Metode Pengembangan Sistem}

Metode Web Engineering adalah urutan langkah yang terstruktur untuk mengembangkan sebuah sistem informasi berbasis komputer dalam referensi, metode pengembangan sistem diistilahkan dengan sistem developmnet methodology atau rekayasa perangkat lunak(software engineering) [6]. Metode Web Engineering terdapat 5 (lima) tahapan untuk dapat mengembangkan suatu perangkat lunak seperti gambar dibawah ini :

Tahapan Web Engineering adalah sebagai berikut :

1. Customer Communication

Komunikasi antar peneliti dengan calon pengguna yang dihubungkan dengan sistem informasi dan sistem akan mendefinisikan hal apa saja yang termuat dalam aplikasi web, misalnya web yang akan dibangun, database yang digunakan, integrasi antara web yang akan dibangun dengan situasi sistem yang sedang berjalan seperti hubungan antara peneliti dengan calon pengguna dan melakukan pengumpulan informasi tentang hal hal yang akan dimuat dalam web ynag melibatkan semua pengguna [6].

2. Planning

Kegiatan ini menggabungkan pembentukan kode kode bisa secara manual maupun otomatis dan pengujian yang sangat dibutuhkan untuk menemukan kekeliruan kekeliruan atau kesalahan dalam kode program komputer yang dihasilkan sebelumnya [6].

\section{Modelling}

Tujuan dari aktivitas adalah untuk menjelaskan hal - hal apa saja yang memang diperlukan / dibutuhkan pada aplikasi yang akan dibangun dan solusi yang ditawarkan yang diharapkan dpat menjawab apa yang tersirat dari hasil hasil analisa dan pengumpulan data [6].

4. Construction

Pembangunan aplikasi web memadukan antara perkembangan teknologi dengan tools pengembangan web yang telah ada diantaranya struktur tabel, struktur menu program dan rancangan antar muka [6].

5. Deployment

Perangkat lunak disajikan kepada pelanggan yang kemudian mengevaluasi produk yang disajikan akan memberikan umpan baik berdasarkan evaluasi tersebut [6]. 


\subsection{Sistem Yang Diusulkan}

Pada diagram ini yang menjadi aktor sebagai admin adalah pegawai dinas pariwisata kota pagar alam dan aktor kepala dinas, sedangkan user adalah masyarakat atau pengguna lainnya. Pada halaman admin harus melakukan login terlebih dahulu untuk masuk ke menu admin agar bisa melakukan kegiatan yang ada pada menu admin seperti mengelola berita, mengelola wisata, mengelola hotel, mengelola restoran, pengunjung, buku tamu dan peta sedangkan kepala agar bisa melakukan kegiatan yang ada pada menu kepala seperti hotel, wisata, restoran dan pengunjung. Untuk user hanya dapat melihat apa yang di inputkan oleh admin.

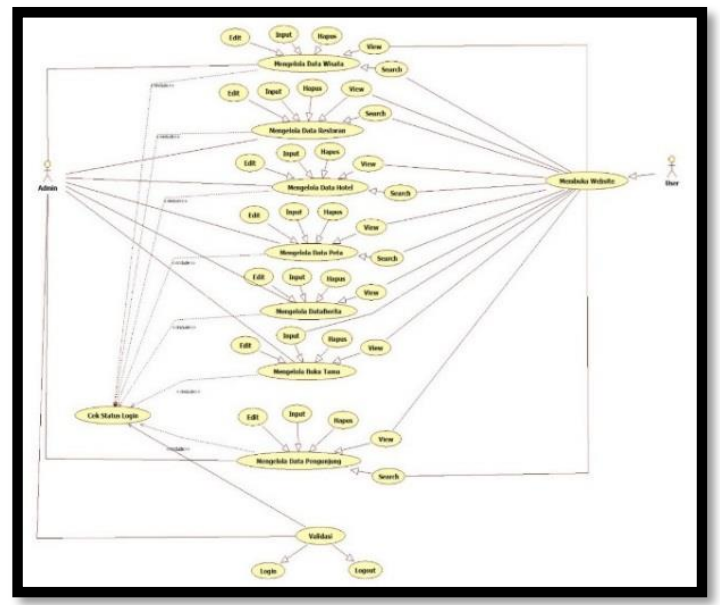

Gambar 1. Use Case Sistem yang Diusulkan

\section{Hasil dan Pembahasan}

\subsection{Halaman User}

Halaman ini adalah halaman pertama kali ketika user mengakses Sistem Informasi Geografis Pariwisata Kota Paga Alam. Pada hlaman ini terdapat berbagai menu yang pertama Home, Pariwisata, Peta Berita, dan Buku Tamu.

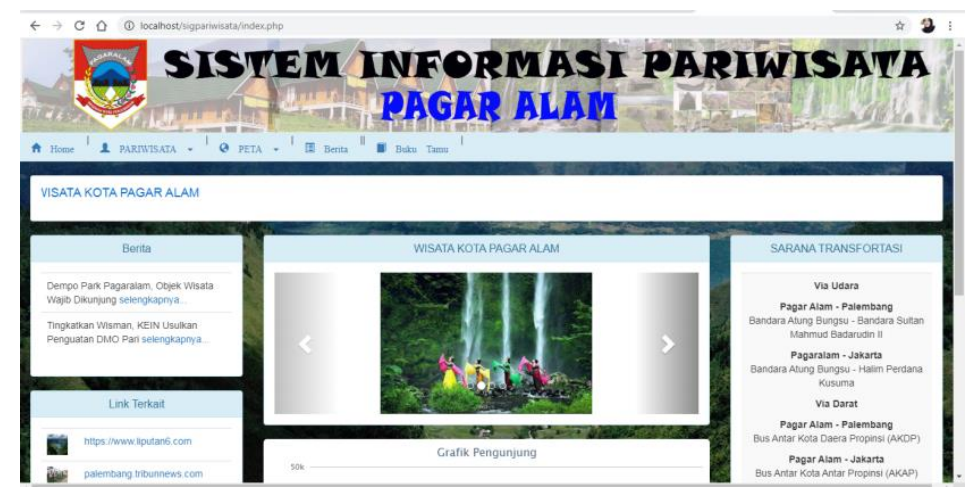

Gambar 2. Halaman User

\subsection{Halaman Wisata}

Halaman ini akan tampil ketika User memilih menu navigasi Pariwisata dan sub menu Wisata. Halaman ini menampilkan tentang Wisata yang ada di Kota Pagar Alam. 


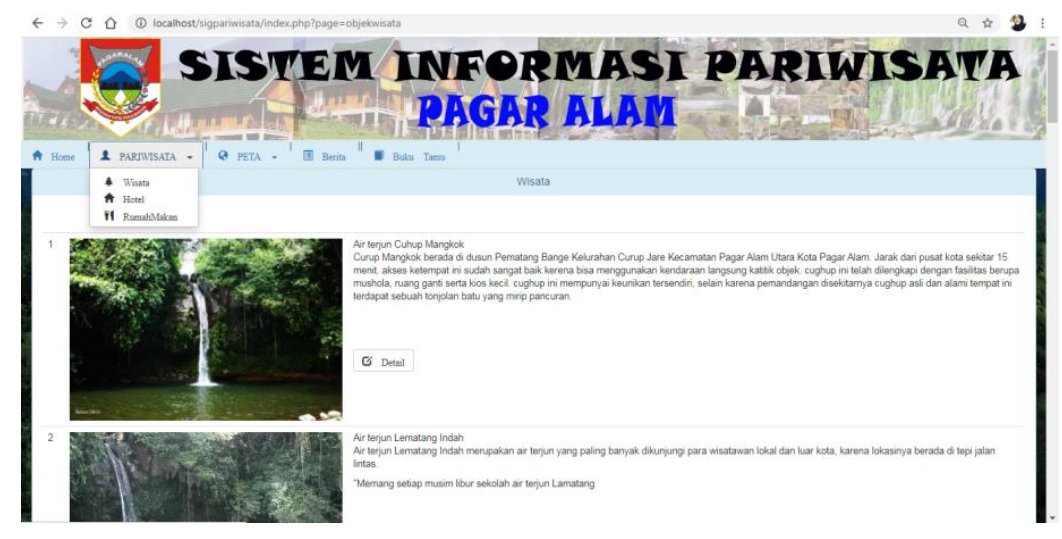

Gambar 3. Halaman Wisata

\subsection{Halaman Hotel}

Halaman ini akan tampil ketika User memilih menu navigasi Pariwisata dan sub menu Hotel. Halaman ini menampilkan tentang Hotel yang ada di Kota Pagar Alam

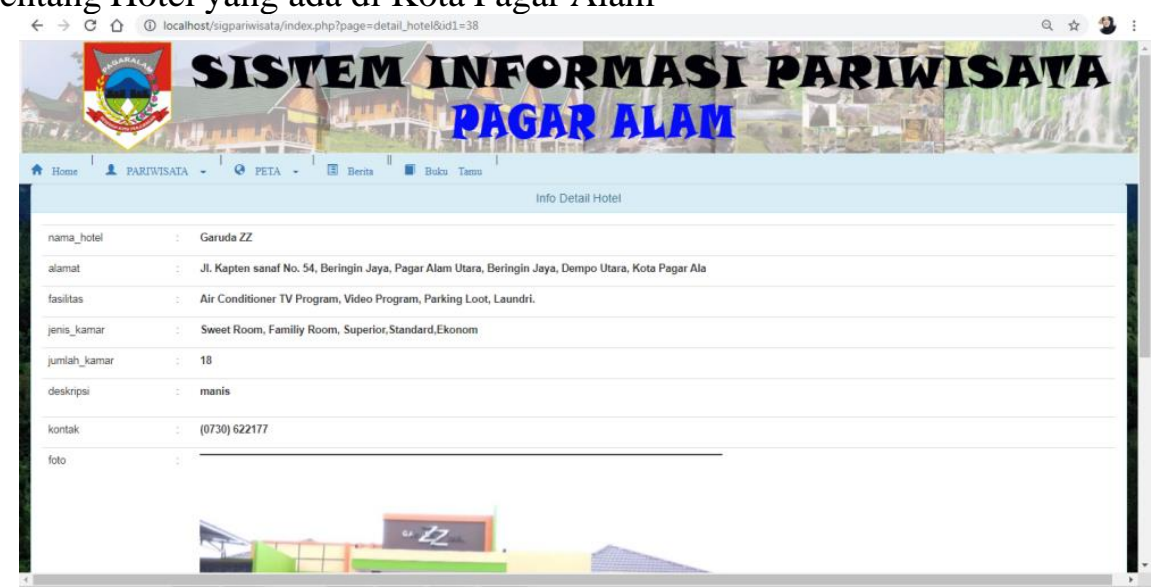

Gambar 4. Halaman Wisata

\section{Penutup}

a. Simpulan

Dalam penelitian ini telah diuraikan proses perancangan dan pembuatan sistem informasi pariwisata kota pagar alam. Berdasarkan hasil analisis maka penulis membuat simpulan :

1. Sistem informasi ini memberikan kemudahan untuk para wisatawan dalam memperoleh informasi.

2. Sistem ini dapat mempermudah wisatawan dalam menentukan rute perjalanan dikota pagar alam.

b. Saran

Untuk pengembangan dari penelitian ini disarankan untuk meningkatkan sistem dengan menambah fitur GIS atau Geographic Information System yang dilengkapi dengan pemetaan titik titik tempat wisata, perhotelan dan restoran.

\section{Ucapan Terima Kasih}

1. Terima kasih kepada Dinas Pariwisata Kota Pagar Alam

2. Panitia Senatik STT Adisucipto Yogyakarta 


\section{Daftar Pustaka}

[1] I. P. A. E. Pratama, Sistem Informasi dan Implementasinya, Bandung: Informatikan Bandung, 2013.

[2] R. A. M.Shalahuddin, Rekayasa Perangkat Lunak, Bandung : INFORMATIKA Bandung, 2018.

[3] E. F. \&. Irnawati, PEMROGRAMAN JAVA WEB (Jsp,Jstl \& servilet), Yogyakarta: GAVA MEDIA, 2015.

[4] A. F.K.Sibero, WEB PROGRAMING POWER PACK, Yogyakarta: MEDIAKOM, 2013.

[5] C. S. Sulistya, Adobe Dreamweaver Cs6, Yogyakarta: ANDI Yogyakrta, 2013.

[6] R. Taufiq, Pengantar Sistem Informasi, Tangerang: Mitra Wacana Media, 2018.

[7] A. Kadir, Pengenalan Sistem Informasi Edisi Revisi, ANDI, 2014. 
